\title{
Método para identificação e caracterização morfométrica de depressões fechadas em áreas de carste subjacente: exemplo da Bacia Sedimentar da Paraíba, Brasil
}

\author{
Method for identification and morphometric characterization of \\ closed depressions in subjacent karst areas: example from the \\ Paraiba Basin, Brazil
}

Saulo Roberto de Oliveira Vital, Universidade Federal do Rio Grande do Norte, Brasil, srovital@gmail.com

(1) https://orcid.org/0000-0002-2028-0033

Alcina Magnólia Franca Barreto, Universidade Federal de Pernambuco, Brasil, alcinabarreto@gmail.com

(1) https://orcid.org/0000-0003-0864-7995

William Sallun Filho, Universidade de São Paulo, Brasil, wsallun@gmail.com

(1) https://orcid.org/0000-0001-8449-3970

Caio Lima dos Santos, Universidade Federal de Pernambuco, Brasil, caiolimageo@gmail.com (1)

Resumo: $O$ presente artigo pretende divulgar um método para identificação, mapeamento e caracterização morfométrica de depressões fechadas em áreas de carste subjacente. A região analisada encontra-se localizada na zona costeira do Brasil e constitui uma de suas bacias sedimentares costeiras, a Bacia Sedimentar da Paraíba. Nessa área, ocorrem bacias fechadas sobre unidades litoestratigráficas de natureza carbonática, recobertas por sedimentos arenoargilosos inconsolidados, indicando um possível carste. No intuito de compreender sua gênese, foram utilizados dados topográficos advindos de cartas topográficas e de Modelos Digitais de Elevação (MDE) para a identificação de padrões de drenagem radial centrípeta e delimitação dos divisores das bacias fechadas. A partir de então, percebeu-se que o MDE apresentou grande potencial para distinção de padrões de drenagem com maior nível de detalhe. Assim, foi possível inferir características morfométricas importantes, tais como: grau de elipsidade e sinuosidade acima de 1, relação profundidade/diâmetro abaixo de 0,1 , áreas acima de $1 \mathrm{~km}^{2}$ e drenagens centrípetas, as quais indicaram, principalmente, forte controle estrutural, evolução predominantemente horizontal e infiltração difusa, que são características típicas de bacias poligonais. Os dados mencionados se mostraram bastante eficientes e satisfatórios, uma vez que permitiram compreender particularidades genéticas primordiais para o estudo de feições dessa natureza.

Palavras-chave: Dolinas; Carste; Depressões; Mapeamento.

Abstract: The present article intends to disclose a method for the identification, mapping and morphometric characterization of closed depressions in the underlying karst areas. The analyzed region is located in the coastal zone of Brazil and constitutes one of its coastal sedimentary basins, the Paraíba Basin. In this area, closed basins occur on lithostratigraphic units of a carbonate nature, covered by unconsolidated sand-clay sediments, indicating a possible karst. In order to understand its genesis, topographic data from topographic maps and Digital Elevation Models (DEM) were used to identify centripetal radial drainage patterns and delimit divisions of closed basins. From then on, it was realized that the MDE had great potential for distinguishing drainage patterns with a greater level of detail. It was then possible to infer important morphometric characteristics, such as: degree of ellipsity and sinuosity above 1 , depth / diameter ratio below 0.1 , areas above $1 \mathrm{~km} 2$ and centripetal drainages, which mainly 
indicated strong structural control, predominantly horizontal evolution and diffuse infiltration, which are typical features of polygonal basins. The aforementioned data proved to be quite efficient and satisfactory, since they made it possible to understand fundamental genetic particularities for the study of features of this nature.

Keywords: Doline; Karst; Depressions; Mapping.

\section{Introdução}

Na Bacia Sedimentar da Paraíba, localizada no estado homônimo, Região Nordeste do Brasil, ocorrem formas de relevo que chamam a atenção por serem muito frequentes e por apresentarem características típicas de depressões originadas por processos cársticos. Essas feições se desenvolvem sobre os sedimentos arenoargilosos mal consolidados da Formação Barreiras, que, em grande parte da referida bacia, repousa de forma discordante sobre os calcários e margas da Formação Gramame.

Em virtude desse contexto geológico, alguns pesquisadores chegaram a Ihes atribuir uma gênese cárstica ou pseudocárstica (Lummertz, 1997; Oliveira, 2001; Melo et al., 2001; Furrier, 2007; Furrier, Vital, 2011; Marinho, 2011; Araújo, 2012), mas, até então, não houve nenhum estudo pormenorizado.

No que tange à discussão da origem desses relevos sobre coberturas siliciclásticas, na literatura científica nacional e internacional, admite-se dois tipos de processos. $O$ primeiro deles está relacionado à ocorrência de intemperismo químico, em que a dissolução é sucedida por erosão mecânica subsuperficial (piping) e colapso de níveis endurecidos, tais como fragipãs e duripãs (Twidale, 1987; Filizola, Boulet, 1996; Filizola et al., 2001; Hardt, 2011; Sauro, 2013). O segundo, se dá a partir da ocorrência de processos de dissolução em calcários soterrados, configurando um carste subjacente (Twidale, 1987; Sallun Filho, Karman, 2007).

Mesmo assim, a descrição de dolinas sobre arenitos e os mecanismos responsáveis por sua gênese ainda constitui um temário pouco abordado, tanto na literatura nacional como internacional, embora algumas ocorrências importantes sejam descritas por Twidale (1987); Sponholz (1994); Soriano e Simón (1995); Sallun Filho e Karmann (2007).

Em alguns casos, o conjunto de formas é classificado como carste, em virtude do processo de dissolução nos próprios arenitos (Wray, 1997; Hardt, 2011), em outros, são descritas como pseudocarste (Maurity, Kotschoubey, 2001; Aubrecht et al., 2011; Aubrecht et al., 2013; Stafford et al., 2013).

O estudo dessas feições no mundo e, especialmente, no Brasil, ainda é muito raro. Talvez porque os processos que as originam ocorrem em subsuperfície, de modo que suas repercussões em superfície são bastante sutis. No caso específico da área de estudo, muitas dessas depressões fechadas foram completamente ou parcialmente soterradas. Além disso, os pontos onde elas se encontram relativamente preservadas, foram bastante descaracterizados pelas atividades antrópicas. Além disso, seus 
mecanismos genéticos, até a realização deste estudo, eram pouco esclarecidos, e seus impactos ainda não causaram sérios danos materiais à população envolvida. Algumas dessas áreas, onde formam-se lagos e lagoas, servem como pontos turísticos, a exemplo da Lagoa do Parque Sólon de Lucena em João Pessoa, Capital do Estado da Paraíba.

No intuito de esclarecer os mecanismos morfogenéticos dessas feições, foi necessário o emprego de uma técnica capaz de delimitá-las, uma vez que, até então não havia nenhuma ideia de sua distribuição geográfica e características morfométricas. Desse modo, o presente artigo pretende discutir essas técnicas, principalmente como um procedimento que possa ser adotado na identificação de outras feições dessa natureza em carste subjacente.

\section{Localização e caracterização geológica-geomorfológica da área de estudo}

A área de estudo encontra-se localizada na faixa costeira do estado da Paraíba, inserida no retângulo envolto pelas coordenadas UTM 257449mE e $297084 \mathrm{mE}$, e 9239778mN e $9197696 \mathrm{mN}$, zona 25 (Figura 1).

Os limites da área estudada detêm uma área total de $1.871 \mathrm{~km}^{2}$, perfazendo parte dos municípios de João Pessoa, Bayeux, Lucena, Santa Rita, Cabedelo, Conde e Alhandra.

\subsection{Geologia e Geomorfologia}

A geologia da área se encontra inserida no contexto das formações geológicas que compõem a Bacia Sedimentar da Paraíba. A mesma é formada por rochas que remontam do Cretáceo, Paleógeno/Neógeno e Quaternário, que se estendem numa faixa de, aproximadamente, $40 \mathrm{~km}$ de largura de extensão, sendo delimitada a Norte pela falha de Mamanguape e a Sul pelo Lineamento Patos (Barbosa, Lima Filho, 2005).

A Bacia Sedimentar da Paraíba apresenta uma sucessão sedimentar principiada por arenitos de origem continental, fluviais e fluvio-lacustres, depositados sobre 0 embasamento cristalino, que constituem a Formação Beberibe, cuja origem remonta do Coniaciano? - Santoniano. Em seguida, ocorrem arenitos calcíferos cuja gênese encontra-se associada ao início de um evento transgressivo que recobriu os depósitos continentais basais, recebendo o nome de Formação Itamaracá, de idade NeoCampaniano-Eo-Maastrichtiano. Por sobre os estratos da Formação Itamaracá ocorrem calcários compactos sem influência de siliciclastos, cognominada Formação Gramame, depositada no máximo transgressivo, durante o Maastrichtiano. Acima destes, e separados por um evento erosivo regional, ocorrem calcários com uma gradativa influência de siliciclastos, por vezes, magnesianos, devido a ocorrência de um evento regressivo que se processou no final do Maastrichtiano, constituindo a Formação Maria Farinha, de idade Paleoceno-Eoceno? (Barbosa, 2007). 


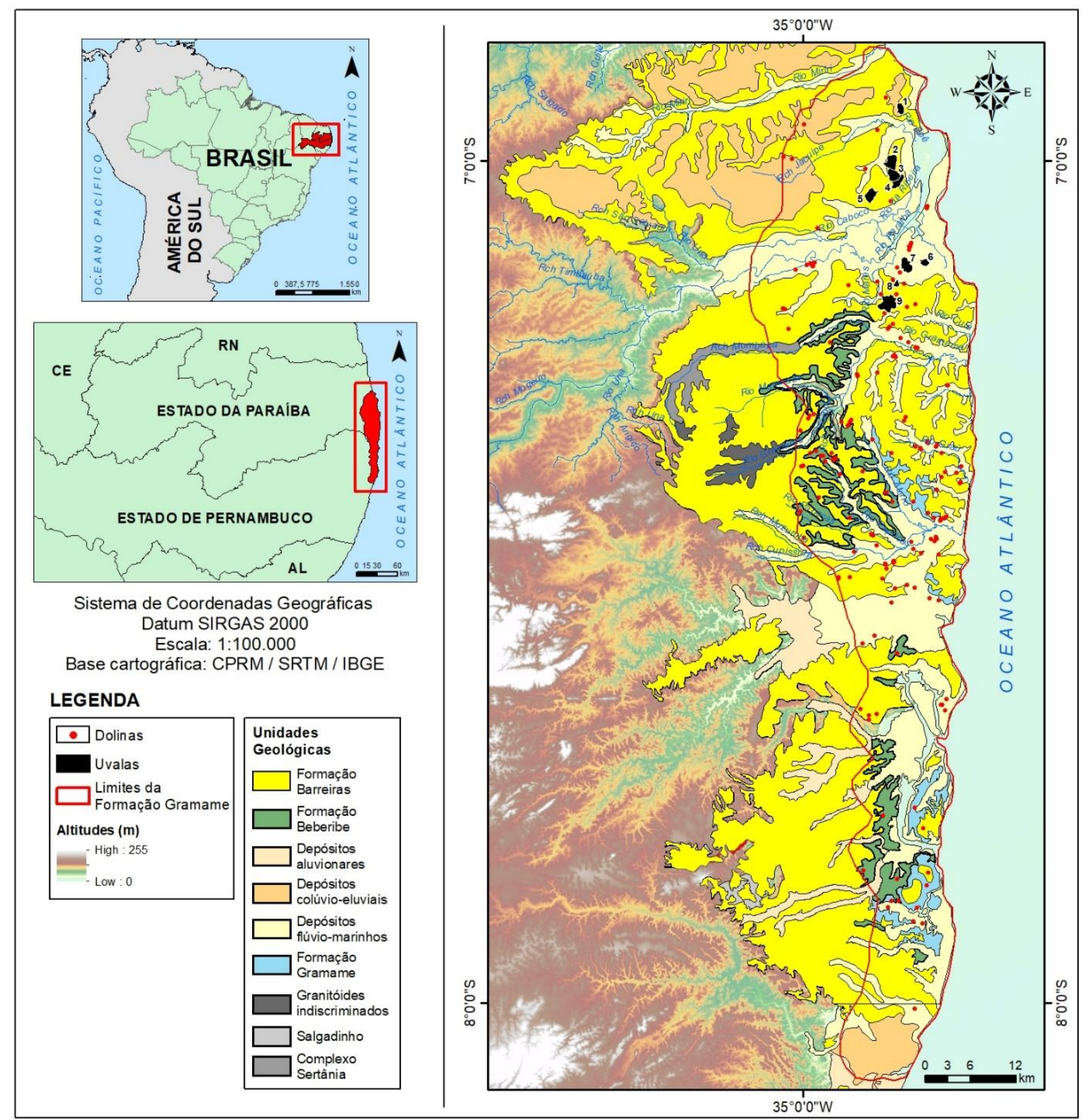

Figura 1: Mapa de localização e geologia da área de estudo e distribuição das depressões fechadas Org.: Saulo Vital, 2020.

Recobrindo os depósitos do Grupo Paraíba ocorrem os sedimentos arenoargilosos da Formação Barreiras. Essa formação abrange grande parte da faixa litorânea brasileira, desde o estado do Rio de Janeiro até o Amapá, se estendendo, ainda, pelas baixadas amazônicas. A mesma se apresenta como uma sequência notável e contínua de sedimentos, pouco ou não consolidados, variando entre argilas e conglomerados, apresentando, normalmente, uma estratificação irregular e muito indistinta (Mabesoone et al., 1972; Mabesoone, Rolim,1982; Arai, 2006).

No norte da Bacia Sedimentar da Paraíba, entre as sub-bacias Alhandra e Miriri, as camadas da Formação Maria Farinha e do topo do Maastrichtiano, correspondentes ao Gramame Superior, desapareceram gradativamente, de modo que a Formação 
Barreiras repousa de forma discordante sobre os calcários da Formação Gramame (Barbosa et al., 2003) (Figura 2).



Figura 2: Limites das bacias Potiguar, Paraíba e Pernambuco

Fonte: Modificado de Barbosa (2007).

Tomando como base a classificação geomorfológica do estado da Paraíba (Carvalho, 1982), a área analisada nesse estudo abrange as seguintes unidades do relevo: Baixada Litorânea, Baixos Planaltos Costeiros (Tabuleiros) e Planícies Aluviais.

A Baixada Litorânea corresponde à área deprimida em relação aos terrenos contíguos (Guerra, Guerra, 2008), na interface continente/oceano, onde os processos morfodinâmicos são determinados por essa inter-relação. Em suma, corresponde à faixa costeira do estado, composta por sedimentos quaternários. Em alguns pontos, essa faixa possui alguns quilômetros de espessura entre a faixa de praia e 0 continente. Dependendo da distância da costa, os processos costeiros já não estão mais ativos, demarcando linhas de paleofalésias.

Os Baixos Planaltos Costeiros, por sua vez, correspondem a planaltos de baixa altitude, que compõem um segundo nível altimétrico da área, variando de 30 a 80 metros, dependendo do ponto. Os referidos planaltos têm sua planura interrompida por vales fluviais incisivos e por depressões fechadas, no caso, objeto central desse estudo. Segundo Furrier et al. (2006), tomando como base o graben do Rio Gramame, a sul, esses tabuleiros são amplamente dissecados, havendo, de acordo com o índice de dissecação da região, um aspecto mais colinoso.

Por fim, as Planícies Aluviais correspondem às planícies de inundação, que são planícies pouco elevadas, acima do nível médio das águas, que são inundadas periodicamente (Guerra, Guerra, 2008).

Os tabuleiros costeiros constituem a unidade de ocorrência das depressões analisadas nesse estudo, podendo haver, também, ocorrências nas planícies aluviais. 


\section{Método para identificação das depressões}

Para a realização da delimitação das depressões fechadas foram utilizados dados de Cartas Topográficas e Modelos Digitais de Elevação (MDE). A partir da análise dos referidos dados, percebeu-se que a visualização da drenagem foi mais clara a partir do MDE, uma vez que se tornou possível extraí-las em diferentes graus de detalhamento. No tocante às cartas topográficas, deve-se destacar, portanto, que a variável de interpretação do analista das fotografias aéreas utilizadas em sua elaboração, foi norteada por objetivos que não demandaram maiores níveis de detalhamento da drenagem. Desse modo, vale ressaltar que o intuito deste estudo foi o de identificar áreas com padrão de drenagem radial centrípeta, seguida da delimitação da bacia fechada a partir de seus divisores. Portanto, o MDE se mostrou mais adequado para esta tarefa.

O MDE utilizado foi proveniente do SRTM (Shuttle Radar Topographic Mission), obtido através do TOPODATA (Banco de Dados Geomorfométricos do Brasil), com resolução espacial de 30 metros, cujas etapas de refinamento encontram-se descritas em Valeriano et al. (2010). De posse desse dado, foram extraídas as drenagens a partir da função Generate Watershed do Global Mapper, baseando-se em informações de acumulação e direção de fluxo dos canais, cujo limiar escolhido para a contagem de drenagem por área foi de 200. Além disso, também foram obtidas as curvas de nível do terreno, a partir da função Generate Contours do Global Mapper, com equidistância de 5 metros, tornando possível a delimitação dos divisores topográficos e a identificação de depressões mais suaves. Para esta e demais rotinas de análise espacial, foram utilizados os Sistemas de Informações Geográficas QGIS e Global Mapper (licença experimental de 30 dias) (Figura 3).

De posse dos limites das depressões, foi possível obter através da ferramenta analysis do Global Mapper, dados morfométricos de amplitude, eixo maior/menor, elipsidade, simetria interna, profundidade/diâmetro, área e perímetro.

As informações de amplitude foram obtidas a partir da diferença entre a altitude máxima e mínima da depressão fechada, onde a altitude máxima equivale ao cume do interflúvio e a mínima ao ponto de convergência das drenagens.

O eixo maior e menor foi obtido a partir da geometria da depressão, com base na medição da distância entre seus divisores, a partir da comparação do polígono da bacia fechada com figuras geométricas, tais como: círculos e elipses.

Os dados relativos à elipsidade foram inferidos a partir da razão entre o eixo maior e menor da depressão, onde os valores abaixo de 0 são representativos de depressões mais circulares que elípticas e valores acima de 1 são mais característicos de feições elípticas. Esse parâmetro é importante para o estudo de depressões dessa natureza, uma vez que a elipsidade está orientada conforme fluxo das águas subterrâneas, de modo que fornece um importante parâmetro para a análise das vias de dissolução da rocha. 


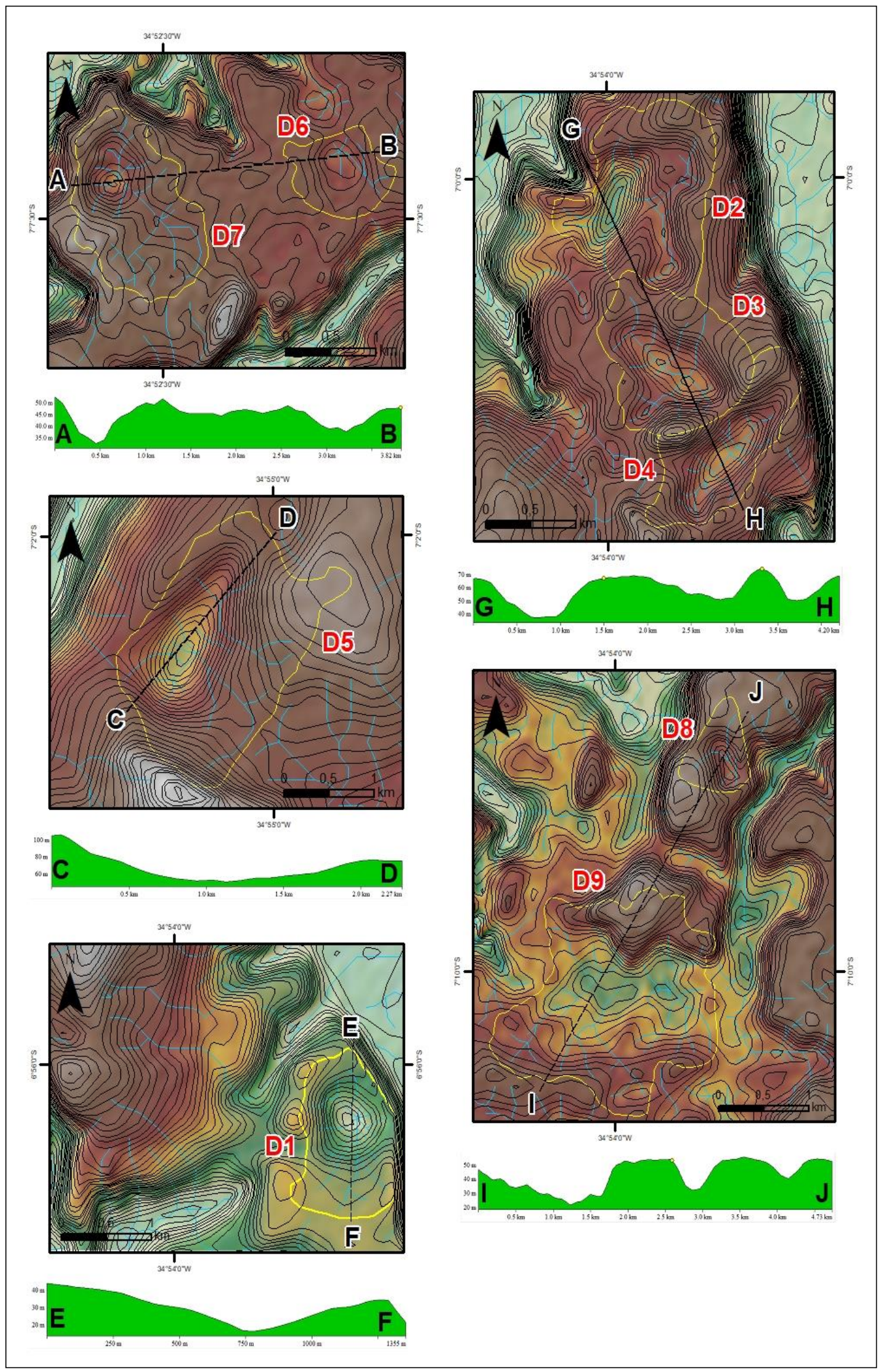

Figura 3: Delimitação das Depressões Fechadas

Org.: Saulo Vital, 2020. 
A simetria interna corresponde à regularidade dos divisores da depressão, sendo obtida a partir da relação entre comprimento e largura entre as partes do eixo longitudinal de cada lado do sumidouro (produto de simetria) (Williams, 1972). A figura 4 representa as medidas que devem ser obtidas para a base de cálculo da simetria interna.

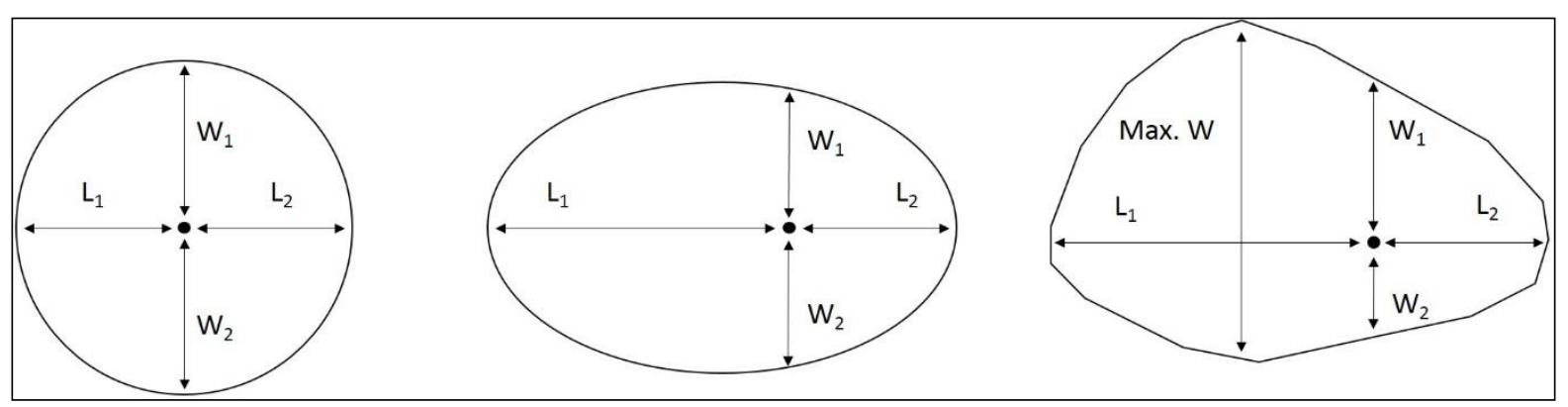

Figura 4: Método para estimativa da geometria bidimensional de uma depressão

Fonte: Adaptado de Williams (1972).

$$
\mathrm{PS}=\mathrm{R} 1 \times \mathrm{RW}
$$

Onde,

Ps $=$ Produto de simetria

$\mathrm{R} l=\mathrm{L}_{1} / \mathrm{L}_{2}$

$\mathrm{R}_{\mathrm{W}}=\mathrm{W}_{1} / \mathrm{W}_{2}$

Os valores de profundidade/diâmetro (P/D) foram estimados a partir do produto entre a amplitude da depressão e seu eixo médio (eixo maior/eixo menor). O P/D é um índice importante no estudo da gênese de depressões cársticas, pois caracteriza quantitativamente a forma em perfil de dolinas, classificando tipos de perfis em suave (abaixo de 1) e íngreme (acima de 1). O perfil íngreme é característico de chaminés, poços, abismos e fendas e o perfil suave é típico de dolinas de sofusão, uvalas e poljés (Figura 5).

Os índices morfométricos de área e perímetro foram obtidos com base no sistema de coordenadas métricas (UTM), assim como os demais. Tais dados são importantes, pois concedem um panorama geral do tamanho das depressões e de seu desenvolvimento horizontal, o que é de grande importância para estudo da gênese de feições dessa natureza.

O Programa QGIS foi utilizado para as rotinas de vetorização e organização final dos mapas. 


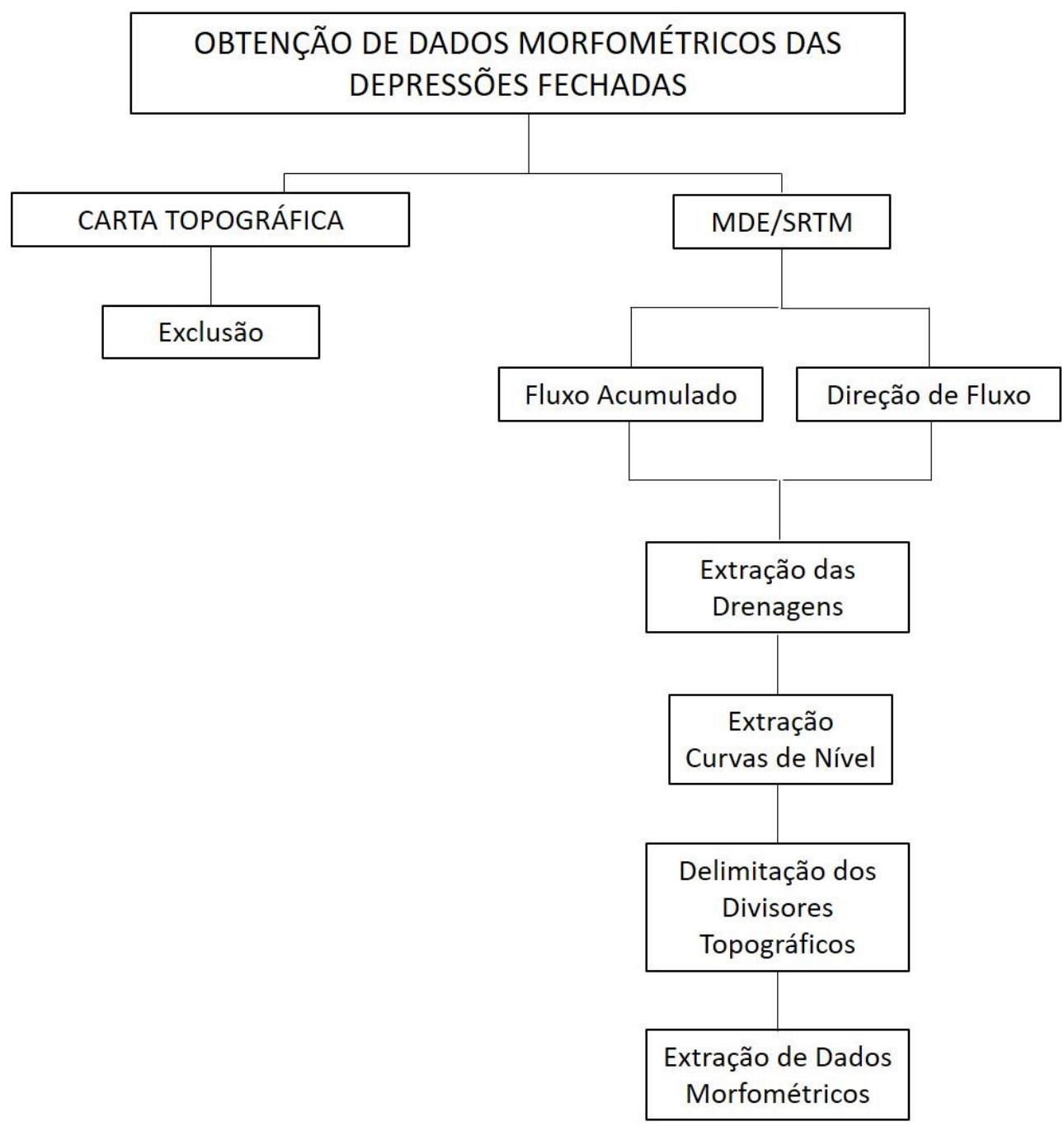

Figura 5: Fluxograma do procedimento metodológico adotado

Org.: Saulo Vital, 2020.

\section{Importância dos dados morfométricos para o entendimento da gênese das depressões fechadas}

O mapeamento das depressões fechadas permitiu reconhecer como elas estão distribuídas geograficamente, suas características morfométricas, as relações com as estruturas existentes na área, com a litoestratigrafia e como essas características refletem em sua gênese.

Com a extração dos índices morfométricos percebeu-se que a maioria dessas feições apresentam extensões acima de um quilômetro quadrado e formas bastante assimétricas, elipsoidais, com eixo maior seguindo direções preferenciais em consonância com os lineamentos regionais.

Inicialmente, foi constatado que suas amplitudes não ultrapassam 35 metros (em média), salvo alguns casos pontuais onde as bacias de grande extensão chegam a alcançar valores de 69 metros. 
A extração de valores relativos à área e ao perímetro chegam a, aproximadamente, 2 $\mathrm{km}$ e $5 \mathrm{~km}$, respectivamente. Ao relacionar a amplitude e extensão (eixo maior) através do índice profundidade/diâmetro (P/D), percebeu-se que as mesmas apresentam ondulação muito suave, remontando a uma gênese provavelmente ligada à subsidência lenta do terreno. A relação profundidade/diâmetro apresenta-se, em média, com valores abaixo de 0,05.

Tal condição foi confirmada através dos trabalhos de campo, onde tornou-se difícil a identificação das depressões, em virtude da suavidade de suas ondulações, e das modificações causadas por meio da ação antrópica. Em alguns casos, observou-se que os fundos das depressões se encontram colmatados por grande volume de material argiloso transportado das vertentes, o que dificulta o contato com as águas subterrâneas. Por muitas vezes, tornou-se difícil enxergar esses pontos, o que induz a entender que constituem áreas de infiltração eminentemente difusa, típico de bacias poligonais.

Foram encontradas muitas áreas deprimidas, com presença de lagoas intermitentes, devido à formação de lençol suspenso. De fato, raramente foi constatada a presença de lagos perenes.

A simetria, que fornece uma medida da regularidade interna das depressões, diminui à medida que os divisores das depressões se tornam irregulares. A maioria das feições apresentam valores acima de 1, caracterizando formas bastante assimétricas.

Em geral, os dados mencionados foram cruciais para compreender que as formas analisadas têm uma origem intimamente ligada a processos de subsidência lenta do terreno. Além disso, a elipsidade e a simetria interna se mostraram bastante esclarecedoras, uma vez que expressaram o condicionamento estrutural ao qual estão submetidas e a atuação dos processos erosivos que contribuem com a sua evolução horizontal.

Algumas destas chegam a apresentar formas muito próximas a bacias fluviais, expondo divisores bastante irregulares, como consequência do processo de ravinamento em suas vertentes, tornando-as bastante sinuosas e alongadas, com exposição de capturas de drenagem.

Um grupo de depressões apresenta apenas um sumidouro principal, com drenagem interna pouco desenvolvida, constituída por pequenas incisões de canais efêmeros, alcançando, no máximo, a segunda ou terceira ordem, com sinais de infiltração difusa.

Aquelas que apresentam extensões maiores, a partir de $1 \mathrm{~km}^{2}$, expõem rede de drenagem interna mais complexa, com mais de um ponto de convergência das águas, apresentando canais de quinta ordem, superfície interna ondulada, vários pontos baixos, inclinação geral centrípeta e eixos que chegam a atingir quilômetros.

Algumas subdepressões não foram notadas através da imagem SRTM, mas foram constatadas através de trabalhos de campo. As características morfológicas dessas áreas apontam para o predomínio do processo de infiltração difusa ao longo de prováveis fraturas e juntas alargadas, ao passo que não foi encontrado um sumidouro 
pontual, a não ser alguns pontos de absorção da água marcados pelo acúmulo de argila, que constituem pontos de concentração da água no período úmido.

Algumas depressões configuram verdadeiras lagoas intermitentes, em virtude da ocorrência de um lençol suspenso, sustentado por níveis endurecidos. No período de estiagem, as águas sofrem uma considerável redução, pois o contato com o aquífero encontra-se interrompido por estes níveis (Figura 6).

Algumas das depressões de maior porte ou primárias representam rotas mais eficientes de escoamento subterrâneo, pelo fato de apresentarem possíveis taxas de abertura e subsidência maior em relação às vizinhas. Aquelas de menor porte, por sua vez, constituem pequenas porções do terreno deprimidas, com algumas centenas de metros quadrados de extensão, dando origem a pequenos lagos de águas temporárias, as quais são presentes em grande número na área estudada.

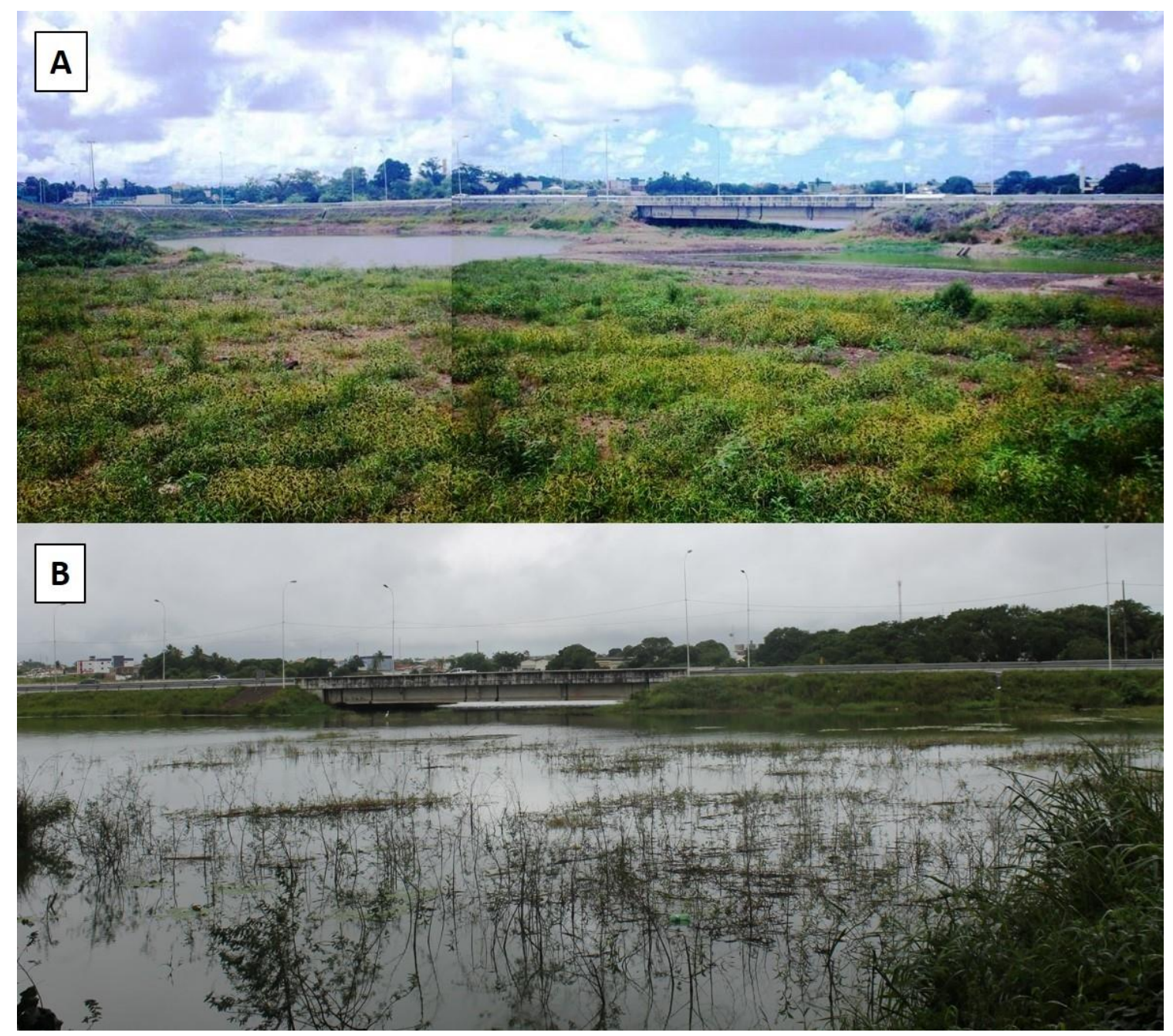

Figura 6: Região das Três Lagoas no período de estiagem (A) e período úmido (B) Fonte: Saulo Vital, 2020. 
As áreas de drenagem centrípeta detectadas a partir do processamento do MDE representam o ponto de maior permeabilidade, onde constata-se a elevação do gradiente hidráulico e a instalação de linhas de fluxo autogênico. A morfologia predominante com uma relação entre profundidade e diâmetro (P/D) muito baixa caracteriza um relevo dominado por vertentes de inclinação bastante suave e fundo plano.

A declividade predominantemente plana e suave ondulada reflete o mergulho estrutural da área, que é de camadas plano-paralelas, com suave inclinação para leste, influenciando, também, no alinhamento do fluxo geral.

A partir da análise dessas características, é pertinente afirmar que as áreas definidas como depressões neste estudo apresentam características semelhantes às uvalas, tendo em vista não somente sua extensão, mas o atendimento de uma série de características inerentes a esse tipo de morfologia, principalmente aquelas ligadas às funções hidrológicas e ao condicionamento estrutural, tais como: (1) ocorrência de perímetros irregulares; (2) dimensões em planta que excedem $1 \mathrm{~km}$ de eixo maior; (3) encostas de inclinação suave; (4) fundos acima do lençol freático, ou seja, em geral, com pouca água, presença de riachos sazonais ou lagoas rasas e; (5) infiltração e dissolução em diversos pontos (difusa); cujas características são descritas por Ćalić (2011) em sua região de estudo.

É importante destacar que, embora a proposta de uma nova conceituação para uvalas tenha se desenvolvido em um contexto marcado por uma litologia carbonática, uvalas também são citadas como feições desenvolvidas em rochas silicosas por Busche e Sponholz (1992) e Hardt (2011). Desse modo, o fato de as reconhecer como uvalas não constitui uma simples distinção de nomenclaturas, certamente vazia, mas possui um significado que vai além disso, sobretudo quando diz respeito a suas características evolutivas.

Em relação ao mapeamento das depressões fechadas, observou-se uma nítida distinção entre a quantidade e o tamanho das mesmas nas regiões norte e sul da área estudada. É perceptível que as maiores depressões se situam na porção centro-norte da bacia, mais especificamente na altura das cidades de João Pessoa e Santa Rita, desde as Três Lagoas até o limite que constitui a região da Mata da Aldeia.

As diferenças de quantidade e tamanho entre as depressões mapeadas pode presumir uma ideia de distintos quadros evolutivos, acentuado pela clara diferença entre os níveis de dissecação da zona norte e zona sul da bacia. De acordo com Furrier et al. (2006), a porção norte da bacia apresenta uma topografia marcada por tabuleiros com superfícies mais extensas, enquanto a porção sul apresenta um aspecto mais colinoso, devido ao maior índice de dissecação.

Nesse sentido, é possível considerar que as depressões encontradas na região norte apresentem extensões maiores em virtude do baixo índice de dissecação da área, onde os tabuleiros mais extensos permitem sua evolução, enquanto aquelas da região 
sul sofreram intensa segmentação a partir de um constante processo de inversão do relevo.

Destarte, a região norte pressupõe a ideia de um carste em um estágio de evolução que tende a progredir a partir de processos de ampliação das dolinas de dissolução e da instalação de novos pontos de absorção vertical. Isso é reforçado pelo fato que não foi detectada nenhuma depressão de grande porte na região sul da bacia.

Também é perceptível que os elementos estruturais demonstram grande influência na gênese e evolução das depressões, cujo controle estrutural é bastante evidente por seus formatos elípticos e eixos bem orientados segundo lineamentos regionais. Desse modo, pode-se afirmar que a geometria das depressões é um forte indicativo de sua origem.

As estruturas identificadas constituem reflexos de reativações cenozoicas do embasamento cristalino, que influenciam os estratos sedimentares sotopostos (Brito Neves et al., 2009), constituindo rotas preferenciais de circulação. A harmonia entre as direções das estruturas e das depressões demonstra que a hipótese ligada à influência da dissolução ao longo dessas linhas de fraqueza da rocha é coerente. Isso significa dizer que, a elipsidade das depressões demonstra claramente 0 condicionamento às estruturas, indicando que a dissolução tem ocorrido nessas linhas preferenciais, determinando a gênese das referidas depressões.

Existe um alinhamento claro entre as depressões fechadas localizadas na zona oeste de João Pessoa, que aparentemente se estendem até os afloramentos de calcário do baixo Roger, condicionando, também, o graben do Rio Sanhauá (Figura 7).

Os anfiteatros também são formas bastante comuns na área de estudo. Alguns chegam a apresentar um aspecto bastante semicircular, constituindo verdadeiros alvéolos, muito semelhantes às depressões, porém apresentando capturas de drenagem. Essas feições devem sua existência à atuação de processos fluviais, com grande influência das oscilações eustáticas desde o mioceno, mas, diante disso, também não se deve excluir a atuação da dissolução em sua evolução. Em suma, a existência de anfiteatros em um ambiente influenciado pela gênese cárstica, sinaliza para a possibilidade de antigas depressões fechadas que foram capturadas pelo sistema fluvial. 


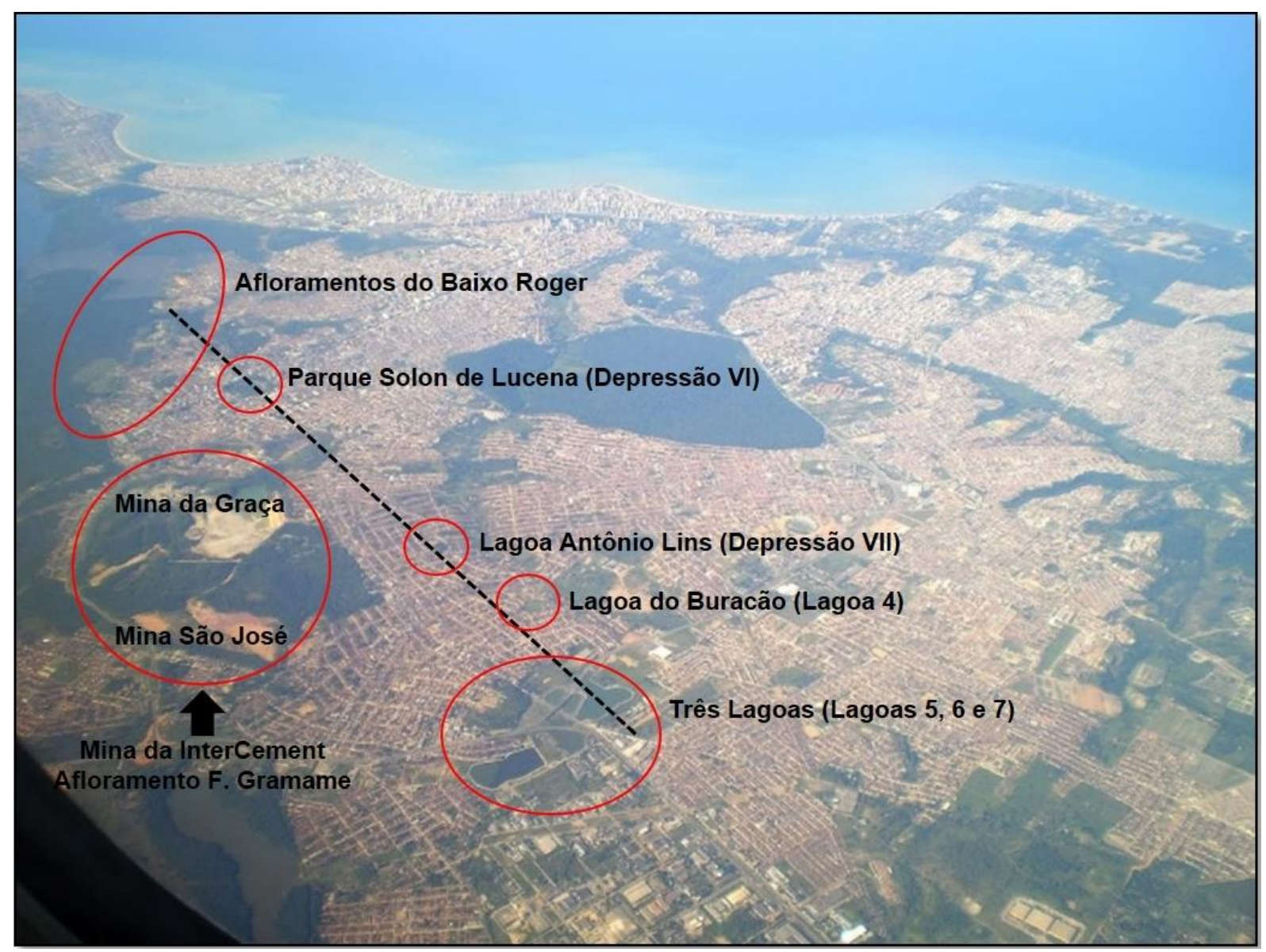

Figura 7: Alinhamento entre dolinas e depressões na zona oeste da cidade de João Pessoa (PB) e ocorrência de calcários subjacentes

Fonte: Adaptado de Paulo Rosa (1998).

\section{Conclusões}

A partir do presente estudo foi possível compreender que os Modelos Digitais de Elevação são eficientes na identificação de depressões fechadas, uma vez que permite uma distinção mais detalhada da rede de drenagem, assim como de seus divisores topográficos.

Outras bases topográficas, a exemplo das cartas, não possuem a mesma eficiência, pois constituem um produto advindo da interpretação de fotografias áreas e que, portanto, possui elementos cujo nível de detalhe das informações advém dos objetivos do intérprete. No caso específico da rede de drenagem, não há nesses documentos, um maior detalhe das drenagens efêmeras, que são muito importantes para a identificação das bacias fechadas.

Conclui-se, portanto, que, para a identificação de feições dessa natureza, é importante utilizar bases cartográficas advindas de levantamentos topográficos primários, isto é: da interpretação de pares estereoscópicos advindos de fotografias aéreas ou imagens de alta resolução, provenientes de satélites ou Veículos Aéreos Não Tripulados; ou Modelos Digitais de Elevação, originados de levantamentos realizados por radares interferométricos. 


\section{Agradecimentos}

Agradeço ao Programa de Pós-Graduação em Geociências da Universidade Federal de Pernambuco e à CAPES, pelo curso de doutorado e pela bolsa concedida.

\section{Bibliografia}

Arai, M. (2006). A grande evolução eustática do Mioceno e sua influência na origem do Grupo Barreiras. Revista do Instituto de Geociências da USP, 6(2), 1-6. https://doi.org/10.5327/S1519-874X2006000300002

Araújo, M. E. (2013). Água e rocha na definição do sítio de Nossa Senhora das Neves, atual cidade João Pessoa - Paraíba. Tese de Doutorado, Programa de Pós-Graduação em Arquitetura Urbanismo, Universidade Federal da Bahia

Aubrecht, R., Lánczos, T., Gregor, M., Schlögl, J., Šmída, B., Liščák, P., Brewer-Carías, Ch., Vlček, L. (2011). Sandstone caves on Venezuelan tepuis: Return to pseudokarst? Geomorphology, 132(3-4), 351-365. https://doi.org/10.1016/i.geomorph.2011.05.023

Aubrecht, R., Lánczos, T., Gregor, M., Schlögl, J., Šmída, B., Liščák, P., Brewer-Carías, Ch., Vlček, L. (2013). Reply to the Comment on "Sandstone caves on Venezuelan tepuis: Return to pseudokarst?". Geomorphology, 197-203. https://doi.org/10.1016/i.geomorph.2012.11.017

Barbosa, J. A. (2007). A deposição carbonática na faixa costeira Recife-Natal: aspectos estratigráficos, geoquímicos e paleontológicos. Tese de Doutorado, Programa de PósGraduação em Geociências. Universidade Federal de Pernambuco.

Barbosa, J. A., Souza, E. M., Lima-Filho, M. F., Neumann, V. H. (2003). A estratigrafia da Bacia Paraíba: uma reconsideração. Revista Estudos Geológicos, 13, 89-108.

Brito Neves, B. B., Albuquerque, J. P. T., Coutinho, J. M. V., Bezerra, F. H. R. (2009). Novos dados geológicos e geofísicos para a caracterização geométrica e estratigráfica da Subbacia de Alhandra (Sudeste da Paraíba). Revista do Instituto de Geociências, 9, 63-87. https://doi.org/10.5327/Z1519-874×2009000200004

Busche, D., Sponholz, B. (1992). Morphological and micromorphological aspects of the sandstone karst of eastern Niger. Z. Geomorph. N. F., 85, 1-18.

Ćalić, J. (2011). Karstic uvala revisited: Toward a redefinition of the term. Geomorphology, 134, 32-42. https://doi.org/10.1016/i.geomorph.2011.06.029

Carvalho, M. G. R. F. (1982). Estado da Paraíba: classificação geomorfológica. João Pessoa: UFPB/FUNAPE.

Filizola, H. F., Boulet, R. (1996). Evolution and opening of closed depressions developed in a quartz-kaolinitic sedimentar substratum at Taubaté basin (São Paulo, Brazil), and analogy to the slope evolution. Geomorphology, 16(1), 77-86. https://doi.org/10.1016/0169$\underline{555 X(95) 00086-\mathrm{K}}$

Filizola, H. F., Lamotte, M., Fritsch, E. Boulet, R., Araújo Filho, J. C., Silva, F. B. R., Leprun, J. C. (2001). Os fragipãs e duripãs das depressões dos tabuleiros costeiros do nordeste brasileiro: uma proposta de evolução. Revista Brasileira de Ciência do Solo, 25(4), 947963. http://dx.doi.org/10.1590/S0100-06832001000400018 
Furrier, M. (2007). Caracterização geomorfológica e do meio físico da folha João Pessoa 1:100.000. Programa de Pós-Graduação em Geografia Física, Universidade de São Paulo.

Furrier, M., Araújo, M. E., Meneses, L. F. (2006). Geomorfologia e Tectônica da Formação Barreiras no Estado da Paraíba. Revista do Instituto de Geociências, 6(2), 61-70. https://doi.org/10.5327/S1519-874X2006000300008

Furrier, M., Vital, S. R. O. (2011). A formação de Dolinas em áreas urbanas: o caso do bairro de Cruz das Armas em João Pessoa (PB). Revista Brasileira de Geografia Física, 4(1), 161-173. https://doi.org/10.26848/rbgf.v4i1.232672

Guerra, A. T., Guerra, A. J. T. (2008). Novo Dicionário Geológico-Geomorfológico. Rio de Janeiro: Bertrand Brasil.

Hardt, R. (2011). Da carstificação em arenitos: aproximação com o suporte de geotecnologias. Tese de Doutorado, Instituto de Geociências e Ciências Exatas, Universidade Estadual Paulista.

Lummertz, F. B. (1977). Aspectos da hidráulica subterrânea na área da Grande João Pessoa. Dissertação de Mestrado, Universidade Federal de Pernambuco.

Mabesoone, J. M., Rolim, J. L. (1982). Problemas estratigráficos e sedimentológicos do cenozóico nordestino. Estudos Pesquisas, 5, 7-18.

Mabesoone, J. M., Silva, A. C., Beurlen, K. (1972). Estratigrafia e origem do Grupo Barreiras em Pernambuco, Paraíba e Rio Grande do Norte. Revista Brasileira de Geociências, 2(3), 173-187.

Marinho, E. G. A. (2011). Bases geológicas e geomorfológicas das organizações espaciais no município de João Pessoa (PB). Tese de Doutorado, Programa de Pós-Graduação em Geociências, Universidade Federal de Pernambuco.

Maurity, C.; Kotschoubey, B. (2001). Pseudokarst features in the lateritic cover of Serra dos Carajás - Pará State, Brazil. In: Anais... International Congress of Speleology, 13., Speleological Congress of Latin América and Caribbean, 4., Brazilian Congress of Speleology, 26. Brasília, pp. 389-411.

Melo, A. S. T., Heckendorff, W. D., Alves, E. L., Guimarães, M. M. M. (2001). O meio ambiente natural: componentes abióticos e bióticos. In: Melo, A. S. T. et al. (Org.). Projeto de Pesquisa: Vale do Jaguaribe. João Pessoa: Ed. UNIPÊ.

Oliveira, F. B. (2001). Degradação do meio físico e implicações ambientais na bacia do rio Jaguaribe - João Pessoa - PB. Dissertação de Mestrado. Programa de Pós-Graduação em Geociências. Universidade Federal de Pernambuco.

Sallun Filho, W., Karmann, I. (2007). Dolinas em arenitos da Bacia do Paraná: evidências de carste subjacente em Jardim (MS) e Ponta Grossa (PR). Rev. Brasileira de Geociências, 37(3), 551-564.

Sauro, F., Piccini, L., Mecchia, M., Waele, J. (2013). Comment on "Sandsatone caves on Venezuelan tepuis: Return to pseudokarst? by R. Aubrecht, T. Lánczos, M. Gregor, J. Schlögl, B. Smída, P. Liscák, Ch. Brewer-Carías, L. Vlcek, Geomorphology 132 (2011), 351-365". Geomorphology, 197, 190-196. https://doi.org/10.1016/i.geomorph.2012.11.015 
Soriano, M. A.; Simón, J. L. (1995). Alluvial dolines in the central Ebro basin, Spain: a spatial and developmental hazard analysis. Geomorphology, 11(4), 295-309. https://doi.org/10.1016/0169-555X(94)00066-Z

Sponholz, B. (1994). Silicate karst associated with lateritic formations (examples from eastern Niger). Catena, 21(2-3), 269-278. https://doi.org/10.1016/0341-8162(94)90017-5

Stafford, K. W.; Shaw-Faulkner, M. G.; Brown, W. A. (2013). Clastic sinkhole and pseudokarst development in east Texas. In: Anais... Sinkdole Conference, 13., Texas, Eua, pp. 36-50.

Twidale, C. R. (1987). Sinkholes (Dolines) in lateritised sediments, western sturt plateau, northern territory, Austrália. Geomorphology, 1(1), 33-52. https://doi.org/10.1016/0169$\underline{555 \times(87) 90005-5}$

Valeriano, M., Albuquerque, P. C. G. (2010). TOPODATA: Processamento dos dados SRTM. Instituto Nacional de Pesquisas Espaciais, São José dos Campos, SP. Disponível em 18 de fevereiro de 2014 em: http://urlib.net/sid.inpe.br/mtc-m19@80/2010/05.10.18.42

Williams, P.W. (1972). Morphometric analysis of polygonal karst in New Guinea. Geological Society of America Bulletin, 83(3), 761-96. https://doi.org/10.1130/00167606(1972)83[761:MAOPKI]2.0.CO;2

Wray. R. A. L. (1997). A global review of solutional weathering forms on quartz sandstones. Earth Science Reviews, 42(3), 137-160. https://doi.org/10.1016/S0012-8252(96)00056-6

Artigo recebido em / Received on: 05/11/2020

Artigo aceite para publicação em / Accepted for publication on: 26/12/2020 
Vital et al. / Physis Terrae, Vol. 2, no 2, 2020, 127-143

Página intencionalmente deixada em branco 